\title{
Arterial Embolization of Hemorrhoids
}

\author{
Pavel G. Tarazov ${ }^{1}$
}

Received: 27 March 2015 / Accepted: 26 April 2015/Published online: 13 June 2015

(C) Springer Science+Business Media New York and the Cardiovascular and Interventional Radiological Society of Europe (CIRSE) 2015

I recently read with great interest the article by Vidal et al. The authors treated hemorrhoids with coil embolization of terminal branches of the superior rectal arteries in 14 patients with promising results [1].

To my knowledge, Galkin was the first who in 1992 assumed that hemorrhoids appeared from pathologically changed cavernous tissue of the rectum and offered arterial embolization for treatment. In 1994, he published the experience with embolization of branches of the superior rectal arteries with polyvinyl alcohol particles and spheres $(0.1-0.6 \mathrm{~mm})$ in 34 patients with good results and no recurrence during 2-year follow-up [2]. In 1998, Galkin et al. reported on embolization of 49 patients with $94 \%$ clinical success [3]. A few years ago Galkin et al. made oral presentation about 237 patients treated by embolization: most patients were free of symptoms with maximal follow-up of 18 years, and only $6.5 \%$ had recurrence. Embolization was well-tolerated by patients and very costeffective [4]. Unfortunately, the above-mentioned authors did not publish their materials in English literature and this fact could complicate the search of these sources.

I have no definitive mind about "emborrhoids". My own (unpublished) experience consists of only two cases. After embolization by particles, both patients experienced significant anal pain and one of them had early bleeding recurrence, so I stopped the clinical use of this method in
1999. Now, after recent reports [3, 4], I begin to think about re-evaluation of embolization method for hemorrhoids. In any case, I will observe the progress of this promising technique with great interest.

Conflict of interest The authors declare that they have no conflict of interest.

\section{References}

1. Vidal V, Sapoval M, Sielezneff Y, De Parades V, Tradi F, Louis G, Bartoli JM, Pellerin O. Emborrhoids: a new concept for the treatment of hemorrhoids with arterial embolization: the first 14 cases. Cardiovasc Intervent Radiol. 2015;38:72-8. doi:10.1007/ s00270-014-1017-8.

2. Galkin EV. Interventional radiology of chronic hemorrhoids. Vestnik Rentgenologii (Mosk). 1994;4:52-6 (in Russian with English abstract).

3. Galkin EV, Yavisya AM, Vdovenko PA. Interventional radiology of chronic hemorrhoids complicated by hemorrhage. Vestnik Rentgenologii (Mosk). 1998;5:21-4 (in Russian with English abstract).

4. Galkin EV, Gladkov VV, Zakharchenko AA (2011) Endovascular treatment of hemorrhoids. In: Abstracts of the Nevskij Radiological Forum, St. Petersburg; 2-5 April 2011. pp 51-52 (in Russian, no English abstract).
Pavel G. Tarazov

tarazovp@mail.ru

1 Department of Angio/Interventional Radiology, Russian

Scientific Center of Radiology and Surgical Technologies,

Leningradskaja st. 70, Pesochny, St. Petersburg 197758,

Russia 